\title{
Human Poisoning with Plants in Kenya
}

\author{
C.K. MAITAI ${ }^{*}$ AND N.N. MUNGAI
}

'Department of Pharmacology and Pharmacognosy, School of Pharmacy. University of Nairobi, P.O. Box $196^{\top} 600202$. Nairobi. Kenya.

\begin{abstract}
Human poisoning with plants is uncommon as often people only eat material known to be non-toxic. In times of food shortage, people are willing to experiment with new plant material such as roots, fruits and mushrooms and this often leads to poisoning. Cooking, a common practice among humans, often destroys plant poisons. Poisonous plants which cause acute and sub-acute poisoning are well known to the local community where they grow, as the cause-effect relationship is easy to establish, unlike those that cause chronic toxicity. Herbal medicine may cause poisoning, but this is rare particularly among experienced practitioners of herbal medicine. In this article several known poisonous plants in Kenya are briefly discussed.
\end{abstract}

Key words: Poisonous plants. human poisoning

\section{INTRODUCTION}

Human poisoning with plants is not common for several reasons. Firstly. humans do not consume plant food materials indiscriminately and often rely on own experience or other documented evidence regarding their safety and palatability. However. children rarely exercise this caution. Similarly. during times of food shortage, people are willing to experiment with new plant materials such as roots, seeds, fruits and mushrooms out of necessity. There are few, if any, poisonous plants not known to the community within the locality where they grow. Surprisingly, animals in the wild also seem to distinguish between safe and poisonous plant material instinctively, unless they are relocated to a totally different geographical region. Secondly. cooking, a common practice among humans renders many poisonous plant materials not only palatable. but also innocuous. Examples of such materials include cassava tubers, onions. garlic and beans. Some fruits which are toxic when raw often become non-toxic on ripening. An example is Blighia sapida. Several poisonous plants used in small quantities in the preparation of herbal medicine cause subclinical. transient. self- limiting symptoms such as nausea and vomiting. These symptoms are often indistinguishable from the symptoms of the disease being treated. Unfortunately some poisonous plants have a cumulative effect manifested only when considerable damage has been done.

Several poisonous plants in Kenya are known but there is little evidence that they have caused human poisoning. These are presented below. Naturally, any medicinal plant material taken in excess will cause poisoning. Strychnos henningsii is a good example.

\section{Cyanide Containing Plants}

Several plants contain cyanogenic glycosides in one or more parts. Fortunately, the majority contains the glycosides either in inedible parts such as roots and leaves or in edible parts but in small quantities. Cassava (Manihot esculanta) is one of the few plants that contain cyanogenic glycosides in edible portions - in significant amounts [1]. The toxicity of cassava is attributed to two glycosides "linamarin" and "lotaustralin", which occur in the ratio of approximately 93:7. When ingested. they release cyanide in the stomach. Cyanide is liberated by the enzymes linamarase and linase found in plants. In small amounts, orally ingested cyanide causes a bitter burning taste, salivation and transient stimulation. Material containing less than $200 \mathrm{mg} / \mathrm{kg}$ of cyanide is not considered to be of toxicological significance. 
The dry roat of cassava may contain over $2.45 \mathrm{~g} / \mathrm{kg}$ cyanide. Two other plants with a high content of cyanide are Adenia volkensii and Phaseolus lunatus (roots). Maitai et al. have determined the cyanide content of various parts of Adenia volkensii [2-3].

The root of Phaseolus lunatus (broad bean) has been used for homicide by some indigenous

people in Kenya but otherwise is inedible. Examples of other plants known to contain cyanide include. corn, sorghum, sweet potatoes. lettuce and peas. Bitter almond (Prunus communis) has traditionally been used as an appetizer. probably on account of its cyanide content.

\section{Plants Containing Atropine-Like Alkaloids}

The most important plants in this category are the Datura species and in particular D.stramonium. Seeds of $D$. stramonium have been known to contaminate wheat during harvesting. A more peculiar case of $D$. stramonium was reported in Kenya a few years ago. A family of 4 had been working in the field until late in the evening when they hurriedly gathered a well-known nonpoisonous vegetable Solanum nigrum. In the process they inadvertently picked young shoots of D. stramonium. Within a few hours of consuming the vegetable. they were rushed to hospital and all showed typical signs of atropine poisoning such as mydriasis. hallucinations. dry mouth. blurred vision and palpitations. They were treated and discharged 2 days later.

\section{Mushrooms}

Many thousands of mushrooms are well known. but only about 100 species have been classified as poisonous and of these less than a dozen are associated with fatalities. A few mushrooms are edible while the greater majority is neither edible nor poisonous. No genus of mushroom is entirely "safe" but some are considered "relatively safe" since no fatal cases have been associated with them. Mushroom identification is considered difficult and often inconclusive. As a result few people will consume wild mushrooms and consequently poisoning is uncommon in Kenya. In some European countries. mushroom gathering from the wild is considered a hobby and this often leads to poisoning. Rumack et al. [4] have compiled a comprehensive account of poisonous mushrooms.

\section{Plants Containing Pyrrolizidine Alkaloids}

There are several plants containing pyrrolizidine alkaloids (PA) and some are found in Kenya. Typical examples include Senecio. Heliotropium and Crotalaria species [5]. Cereal grains contaminated with seeds of PA have caused human poisoning in Afghanistan, India, South Africa. and USSR but no such cases have been reported in Kenya. Some of the PA containing plants are used in preparation of herbal medicines and tonics. A typical example is Senecio moorei (Mount Elgon Ragwort), which was investigated by Maitai et al. [6].

PA are metabolized in the liver to toxic metabolites. pyrrolic dehydro alkaloids, which are reactive alkylating agents. The metabolites are eliminated from the body, mainly in urine within a few hours so that none is detectable in the body tissues and fluids after 24 hours. The toxic effects of PA are cumulative even though they do not accumulate in the body. Symptoms of poisoning are acute in onset and usually characterized by upper abdominal discomfort that develops rapidly and progresses to the swelling of feet. The disease is called veno-occlusive disease (VOD) because of the characteristic obstruction of the small venous blood vessels that carry blood back to the liver from the heart. Mortality resulting from VOD is high. The toxic effect of PAs occurs primarily in the liver.

\section{Mycotoxins}

These are toxic products of microscopic fungi commonly found in foodstuff under unfavourable storage conditions of humidity and temperature. In Kenya, the most common are the aflatoxins produced by certain strains of Aspergillas flavus and $A$. parasiticus under optimum conditions of humidity $(85 \%)$ and temperature $\left(27^{\circ} \mathrm{C}\right)$. So far, approximately 17 aflatoxin compounds have been isolated [7]. Out of these. 4 aflatoxins $B_{1}, B_{2}, G_{1}$ and $G_{2}$ often occur simultaneously in the cereals. In Kenya. epidemic aflatoxin poisoning was reported in Machakos District in 2004 after people ate contaminated maize imported from overseas 
following a food shortage. Whole families of between five to eight members haye been wiped out with serious political ramifications.

Aflatoxin poisoning has occurred when rotten or mouldy maize "unfit for human consumption" has instead been used to make illicit traditional brews. In other cases. the rotten maize has been fed to dairy animals and subsequently the aflatoxins are excreted in milk. Aflatoxin poisoning has been reported in dogs fed on contaminated dog food (personal communication from the Government Chemist).

\section{Plants Containing Selenium}

Plants including cereals and vegetables readily absorb selenium. Two classes of seleniferous plants are recognized. Firstly, there are "obligate" or "indicator" plants that grow only where there is selenium in the soil in large amounts. These plants accumulate selenium and then release it in a form readily absorbed by other plants such as maize. wheat. cabbage. onions etc. Secondly there are "facultative" or "secondary" selenium absorbers. which grow in soils free of selenium but can accumulate it in large quantities if it is present. Soil rich in iron oxide (red soil) binds selenium as insoluble basic ferrous selenite. making it unavailable to plants. Selenium poisoning is common in herbivores and was first described under the name "Alkali disease " but in humans it is almost unheard of.

\section{Plants Containing Oxalate}

Several common plants used as vegetables contain oxalate salts. These include amaranth. sugar beet, Rumer species. spinach. and rhubarb. Oxalates consumed in large amounts may precipitate in the kidney as insoluble calcium oxalate crystals and cause hematuria. The amounts of oxalate in most vegetables are probably too small to cause toxicity and are often removed during cooking.

\section{Plants Containing Nitrates}

Several plants contain nitrate/nitrites in the edible parts. The amount is probably too small to convert a significant amount of haemoglobin to methaemoglobin in humans. Several cereals, for example oats. have nitrites but in amounts too small to cause hypoxia. The degree of hypoxia is proportional to the quantity of methaemoglobin formed.

\section{Plants Containing Fluoroacetate}

Some plants are known to concentrate sodium fluoroacetate. one of the most poisonous substances known. In Kenya, Dichapetalum cymosum is found in the coastal region. where it is known as "Ludi" locally. A few leaves are capable of killing a big bull. In South Africa the plant is known as gifblaar. Fortunately, humans do not eat this material.

\section{Stinging Plants}

There are several stinging plants in Kenya. When the stinging part comes into contact with human skin. it causes extreme pain and even shock. Maitai et al. have reported on Uirtica massaica [8] and Obetia pinafida [9].

\section{Plants Causing Contact Dermatitis}

Several plants. particularly in the family Euphorbiaciae. contain milky latex. which on contact with skin and mucous membrane causes serious inflammation. One such plant is Synadenium compactum. which has caused problems particularly in children. It contains acrid. vesicant latex.

\section{Plants Containing Cardiac Glycosides}

Several plants containing cardiac glycosides are found in Kenya. Most important are the Acocanthera species used to make poisoned arrows. These poisoned arrows are lethal and were used during tribal and clan fighting. They are traditionally used in hunting wild animals. The details on the arrow poisons are published by Maitai et al. [10]. Other plants containing cardiac ylycosides include Nerium oleander, Thevetia perwiana and some Strophanthus species. There .is no evidence that these have caused human poisoning.

\section{Ergot (Claviceps purpurea)}

This parasitic fungus grows on cereal grains such as wheat, rye. barley, oats and sorghum. The most important compounds in Ergot are ergotamine and ergocristine. A common symptom of poisoning is 
gangrene of the extremities. There has been suspicion that some of the symptoms observed in children could be due to ergot poisoning but no evidence has been adduced. More information on ergot poisoning is given in literature [11].

\section{MISCELLANEOUS}

There are many other known poisonous plants found in Kenya but since they are not edible, they are not important in human poisoning. These include the following; Phytolacca dondecandra, Cassia didymombotrya,Croton species. Nicotiana glauca. Abrus precatorius. Ferula communis and Warbugia ugandensis.

\section{CONCLUSION}

It is quite clear from the foregoing discussion that although there are many plants in Kenya that can cause human poisoning if ingested. this has not always been the case. However this cannot be said to be so with children and during times of food shortage. It is because of this that these plant sources of poisoning need to be properly documented. This information is useful particularly when dealing with cases of poisoning in our hospitals. This would go along way in ensuring that the cases are handled appropriately and swiftly.

\section{REFERENCES}

[1] W.C. Bowman and M. J. Rand. Textbook of Pharmacology. Blackwell Scientific
Publications, Oxford $2^{\text {nd }}$ ed.(1980) 45

[2] C.K. Maitai. A.T.D Gondwe and I.A. Kamau. Am. J. Vet. Res. 35 (1975) 829831.

[3] C.K. Maitai. A.T.D Gondwe and J.A. Kamau. Bull. Epizoot. Dis. Afr. 22 (1974) 157-60.

[4] H.B. Rumack. Mushroom Poisoning: Diagnosis and Treatment CRL Press Inc 2255, Palm Beach Lake, U.S.A.

[5] Environmental Health Criteria 80 Pyrrolizidine Alkaloids̄. WHO. Geneva (1988).

[6] J.A. Kamau and C.K. Maitai. Bull. Epizoot. Dis. Afr. 23 (1975) 109-112.

[7] Mycotoxins Environmental Health criteria. II WHO. Geneva (1979).

[8] C.K. Maitai. S. Talalaj. D. Njoroge and R.W. Wamugunda. Toxicon. 19. (1981) 186-188.

[9] C.K. Maitai. S. Talalaj. D. Talalaj and D Njoroge. Toxicon. 19. (1981) 186-188.

[10] C.K. Maitai. N. Muraguri and H.A. Patel. E. Afr. Med. J. 50 (1973) 100-4.

[11] Environmental Health Criteria 105 WHO, Geneva, (1990). 